\title{
Tipo de cambio nominal \\ y apreciación cambiaria en México
}

\author{
Nominal exchange rate appreciation in Mexico
}

Daniel Alberto Pérez Ruiz "

\section{Resumen}

El régimen de libre flotación del tipo de cambio vigente a partir de diciembre de 1994 en México, no se diferencia del régimen de bandas cambiarias que predominó de 1991 a 1994. En realidad, no se ha dejado flotar el tipo de cambio y éste no ha sido determinado libremente en el mercado sin la intervención de las autoridades monetarias. Más bien, el banco central y la Comisión de Cambios han hecho uso de las dos principales herramientas -tasa de interés y reservas internacionales- para incidir sobre la determinación del tipo de cambio, tratando así de mantener dicha variable relativamente estable con miras a que ello no tenga un impacto significativo sobre precios. Los mercados cambiarios en la era moderna, se han caracterizado por mostrar un número de transacciones cambiarias con motivos financieros extremadamente mayores que multiplican el volumen operado por transacciones comerciales. El caso de México no ha sido la excepción dada su condición de economía abierta, los flujos de capital se han convertido en la fuerza dominante para fijar los tipos de cambio, lo que ha repercutido en una sobrevaluación del tipo de cambio nominal, colocando a la economía nacional en un contexto de vulnerabilidad.

Palabras Clave:

- Economías domésticas

- Gobierno y sistema monetario

- Bancon centrales y sus políticas

\section{Abstract}

The free-floating regime that has been enforced since December 1994 in Mexico, was portrayed as a better outcome for the economy, however the goals of the authorities were similar to the banded regime from 1991 to 1994. In fact, the Central Bank and Exchange Commission still do not permit the currency to float. Furthermore, an active monetary intervention prevents the currency from being determined by the market. Rather, the central bank and the Exchange Commission have been using the two main tools -interest rates and reserves- to influence in the exchange rate determination. These organizations are working to maintain stable exchange rates in order to fluctuations or changes in domestic prices. The foreign exchange markets in the modern era have been characterized for showing an increasing number of exchange transactions primarily for financial reasons, overcoming the volume of trade transactions. Mexico has made no exception. Given its nature as an open economy, the capital inflows have become the dominant force in setting exchange rates, and it has had a direct impact in a stronger nominal exchange rate overvaluation, placing the national economy in a high vulnerable environment.

\section{Keywords:}

- Domestic Economies

- Government and Monetary System

- Central Banks and Their Policies

JEL: D1, E42, E44, E58

\section{Introducción}

Realmente se trabaja con un tipo de cambio flexible en México? Es una de la preguntas que se plantean en la presente investigación, existe o no de un tipo de cambio flexible en la economía mexicana: en el presente apartado se busca dar respuesta a esta interrogante, y se analiza el punto de vista de las autoridades, así como las diversas posturas y ventajas entorno al tipo de cambio flotante, al igual que el análisis del régimen de tipo de cambio fijo. Finalmente se analiza la fuerte incidencia de los flujos de capital y la apreciación del tipo de cambio. 
Existe una serie de regímenes de tipo de cambio entre las definiciones "estándares" de tipo de cambio fijo y flotante que se señalan en la mayoría de los libros de texto. Situarse en el tipo de cambio fijo o flotante es hablar de polos opuestos, el Banco de México, sostiene que trabaja con un tipo de cambio flotante a partir de la crisis de balanza de pagos de 1994-1995, no obstante existe un debate entorno a esto como se expondrá más adelante.

Es de trascendental importancia conocer la rica variedad de regímenes de tipo de cambio que existen entre las posiciones de esquina o "corner positions", Frankel (2003) distingue nueve regímenes agrupados en tres categorías flotante, intermedio y fijo.

\section{Regímenes de Tipo de Cambio*}

\begin{tabular}{|c|c|c|}
\hline Flotación & Régimen Intermedio & Fijo \\
\hline $\begin{array}{l}\text { Libre Flotación (Free Floating): } \\
\text { Flotación del tipo de cambio por } \\
\text { las libres fuerzas del mercado }\end{array}$ & $\begin{array}{l}\text { Banda Cambiaria (Band): } \\
\text { La banda es definida de acuerdo a } \\
\text { una paridad central fija. } \\
\text { Son diseñados para capturar el ob- } \\
\text { jetivo de Bergsten-Williamson (Fun- } \\
\text { damental Equilibrium Exchange } \\
\text { Rate) y la de Krugman }\end{array}$ & $\begin{array}{l}\text { Regímen de Convertibilidad } \\
\text { (Currency Board): } \\
\text { El sistema fija la moneda nacional } \\
\text { a la moneda extranjera (el dólar). } \\
\text { Es decir, el valor que se fija de la } \\
\text { moneda es equivalente al valor de la } \\
\text { moneda extranjera }\end{array}$ \\
\hline $\begin{array}{l}\text { Flotación manejada (Managed } \\
\text { Floating): } \\
\text { Las autoridades monetarias única- } \\
\text { mente intervienen ocasionalmente } \\
\text { y en pequeños montos. Puede ser } \\
\text { catalogado como régimen interme- } \\
\text { dio si las autoridades intervienen } \\
\text { de manera continua en busca de } \\
\text { un objetivo de inflación }\end{array}$ & $\begin{array}{l}\text { Mini devaluaciones sucesivas } \\
\text { (Crawling Peg): } \\
\text { Es el sistema en el cual la fijación } \\
\text { cambia usualmente para acomodar } \\
\text { la inflación. Permite mantener la } \\
\text { competitividad por medio de anun- } \\
\text { ciar devaluaciones }\end{array}$ & $\begin{array}{l}\text { Dolarización } \\
\text { (Dollarization/euro-ization): } \\
\text { Adopción por parte de un país de } \\
\text { una moneda extranjera fuerte como } \\
\text { el dólar o el euro }\end{array}$ \\
\hline & $\begin{array}{l}\text { Basket Peg: } \\
\text { La moneda es fijada relativa a una } \\
\text { canasta de monedas de los socios } \\
\text { comerciales }\end{array}$ & $\begin{array}{l}\text { Unión Monetaria (Monetary Union): } \\
\text { Sistema de tipo de cambio fijo irre- } \\
\text { vocable. En este régimen dos o más } \\
\text { países usan la misma moneda que } \\
\text { es manejada por una sola autoridad } \\
\text { monetaria. Dicha autoridad puede } \\
\text { estar bajo la responsabilidad de los } \\
\text { países miembros,o bien, por uno de } \\
\text { los miembros }\end{array}$ \\
\hline & $\begin{array}{l}\text { Adjustable Peg: } \\
\text { Se cuenta con una tasa central fija, } \\
\text { pero esta puede ser cambiada para } \\
\text { acomodar desequilibrios de Balanza } \\
\text { de Pagos }\end{array}$ & \\
\hline
\end{tabular}

Fuente: Frankel (2003).

Nota: *Traducción del autor. 
Las así llamados posiciones de esquina se encuentran en los extremos de la tabla, contando desde la primera celda -la libre flotación- con el régimen de tipo de cambio más flexible hasta la última celda del lado derecho -Unión Monetaria- con el régimen más rígido.

Lo anterior permitirá ir moldeando la respuesta a la pregunta de la existencia o no de un tipo de cambio flexible en nuestro país, al presentarse esta gama de regímenes intermedios de tipo de cambio.

Es de interés conocer las ventajas de la libre flotación del tipo de cambio, sistema que de acuerdo al banco central en nuestro país opera actualmente. Baqueiro, et al (2003) sostienen que "el argumento principal a favor del establecimiento de regímenes de tipo de cambio flexible es que la política monetaria no se encuentra restringida por un nivel predeterminado de tipo de cambio y ello permite determinar las tasas de interés de forma tal que se consiga un equilibrio interno (i.e. estabilidad de precios)" (p. 5). Es decir, con ello se logra trabajar con una política monetaria independiente contrario a lo que sucedería de trabajar con un tipo de cambio fijo. Sostiene además que una de las bondades es que la política monetaria logra constituirse como el ancla nominal de la economía y mantiene estabilidad de precios, con ello el banco central puede utilizar las tasas de interés para contrarrestar el ciclo económico.

Esto último es congruente con la idea de un banco central independiente, de acuerdo a Macdonald (2007) trabajar con un régimen de tipo de cambio flotante permite al banco mantener dos ventajas potencialmente importantes: señoreje y fungir como prestamista de última instancia. Este último de mayor importancia ya que en "una crisis bancaria la habilidad del banco central para crear fondos ilimitados puedes ser importante para el rescate de bancos" (p. 31).

Dentro del planteamiento de Wray (2012) se analiza, en relación con lo antes mencionado, que un régimen de tipo de cambio flotante asegura que el gobierno tiene mayor libertad para perseguir objetivos tales como pleno empleo, crecimiento económico y estabilidad de precios.

Además de ello, "cuando la economía se ve afectada por una perturbación adversa a los términos de intercambio, la depreciación necesaria del tipo de cambio real se logra mucho más rápido cuando se deprecia el tipo de cambio nominal que cuando se espera que disminuya el nivel de precios" (p. 5), es decir que al verse afectados los términos de intercambio se logra un ajuste de mucho mayor rapidez por medio de la depreciación del tipo de cambio nominal que esperar la caída del nivel de precios. 
Ronald MacDonald (2007) señala que una ventaja del los regímenes de tipo de cambio flexibles es que ofrecen estabilidad en la economía, siendo éste un factor clave para que Friedman estuviese a favor del tipo de cambio flexible. "Debido a una falta de un mecanismo de ajuste efectivo, los regímenes de tipos de cambio fijos eran propensos a ataques especulativos y crisis periódicas. De hecho, la naturaleza de la estabilización de las expectativas bajo un sistema de tipo de cambio flotante fue visto como un elemento clave en la generación de un entorno tranquilo" (p. 30).

Como es conocido, la libre flotación permite también que se aísle a la economía de choques externos ya que absorbe los efectos de éstos. Esto es por la forma de los choques de comercio, es decir una caída de la demanda de las exportaciones hacia el resto del mundo se reflejará en una depreciación del tipo de cambio por lo que se caen los términos de intercambio, generando lo primero una compensación y por tanto un estímulo en la demanda.

Señala MacDonald (2007) otra de las ventajas de los regímenes de tipo de cambio flexible es "la habilidad de permitir a la economía mundial funcionar sin barreras al comercio y tarifas. La idea es que si el tipo de cambio es capaz de equilibrar la balanza de pagos del país, la necesidad de políticas proteccionistas -tales como tarifas y cuotas- es limitado" (p. 31).

Finalmente otro argumento a favor de los regímenes de tipo de cambio flexible, siguiendo a MacDonald (2007) gira en torno a la necesidad de mantener reservas de moneda extranjera, en el sentido de que ante la no intervención de las autoridades en el mercado de divisas, el cambio de reservas es cero, por lo que habrán pequeños ahorros para la economía nacional, y ante tal situación, el Banco Central sólo debe de mantener reservas para pagar las transacciones comerciales oficiales (p. 31).

En contraposición a ello se encuentra en planteamiento de Wray (2012) señalando que el gobierno no debe temer quedarse sin reservas internacionales por la simple razón que no compromete el pago de moneda nacional por moneda extranjera a una tasa fija o un tipo de cambio fijo. Menciona, "en la práctica, los gobiernos que operan con tipos de cambio flotantes mantienen reservas de moneda extranjera, y ofrecen servicios de cambio de moneda extranjera para la conveniencia de sus instituciones financieras" (p. 151).

En contraposición al tipo de cambio flotante se encuentra el tipo de cambio fijo, por lo que es necesario conocer las principales ventajas que la literatura señala sobre dicho régimen de tipo de cambio. Respecto a esto, MacDonald (2007) señala como una de las principales, de acuerdo a los defensores de este régimen, el prevenir a los países que persigan una política 
monetaria independiente que es vista como, otorgar un sesgo inflacionario a la economía.

De acuerdo a MacDonald (2007) "Si el banco central ata el tipo de cambio a una moneda dura, con una fuerte reputación anti-inflacionaria 'importando' la credibilidad de un ambiente de baja inflación” (p. 31), por ello que los precios y salarios serán fijados bajo una expectativa de baja inflación, con ello, el atar el tipo de cambio a una moneda fuerte permite al banco central expandir la oferta monetaria.

Al respecto Wray (2012) señala que el gobierno debe utilizar la política económica para mantener el tipo de cambio a la paridad a la que se comprometió a pagar, por lo que se pierde el margen de acción de la política económica. Por lo que esta ventaja de importar la credibilidad de un ambiente de baja inflación traería consigo una pérdida del manejo de la política económica con miras a estabilizar el tipo de cambio a cierto nivel.

Una segunda ventaja de acuerdo MacDonald (2007), es la certeza que un régimen de este tipo otorga en las decisiones de inversión y de comercio, ya que removiendo la incertidumbre que se deriva de la volatilidad del tipo de cambio se daría paso a una mejora en el comercio internacional y la inversión.

Finalmente, continuando con MacDonald el tipo de cambio fijo permite "prevenir devaluaciones competitivas o de 'empobrecer al vecino' (beggarthy-neighbour)" (p. 32).

Una vez que se conocen las ventajas del régimen de tipo de cambio flotante $^{1}$ y el esbozo presentado de los regímenes intermedios y el polo opuesto (tipo de cambio fijo) es necesario analizar y poner en cuestión si la política cambiaria en México ha sido realmente la de un régimen de tipo de cambio flexible.

\section{Régimen de tipo de cambio en México ¿flotante o semi-fijo?}

Una de las preguntas que deben de plantearse antes de dar respuesta a la que ocupa el presente apartado, es cuál es el motivo, razón o factores que llevan a una economía a optar por un régimen de tipo de cambio específico. MacDonald (2007) sostiene la existencia de una amplia gama de estudios que intentan encontrar evidencias empíricas acerca de los determinantes de un régimen de tipo de cambio, siendo las variables 'tamaño de la economía'

${ }^{1}$ Se analiza predominantemente el tipo de cambio flotante puesto que de acuerdo al Banco de México es el que actualmente opera en nuestra economía. 
e inflación como las que producen una relación consistente con la variable régimen de tipo de cambio.

El Fondo Monetario Internacional (FMI) refleja en el Annual Report on Exchange Arrangements and Exchange Restrictions (AREAER) la descripción de los acuerdos de tipo de cambio, sistemas de comercio y controles de capital de los países que forman parte del Fmi. En el, se observa cómo en el marco de la política monetaria de cada país, es consistente con diferentes regímenes de tipo de cambio; para el caso de México es catalogado con un régimen detipo decambioflexiblecon una política monetaria basada en objetivos de inflación o inflation-targeting.

De acuerdo al AREAER (2012) el régimen tipo de cambio en México pasó de ser flotante a ser catalogado como de libre flotación, este paso se dio debido a que desde noviembre de 2011 México dejó de intervenir en el mercado de divisas, de acuerdo a la clasificación del FMI. ${ }^{2}$ Cabe recordar que el Banco de México a partir de la crisis económica mundial de 2008 utilizó el mecanismo de subastas ${ }^{3}$ para intervenir en el mercado de divisas.

El Banco de México señala que es a partir de la crisis de balanza de pagos en 1994-1995 cuando se toma a la política monetaria como el ancla nominal en la economía, al optar por un régimen de tipo de cambio flotante, ello acorde a la modificación en el esquema a seguir de la política monetaria, trayendo consigo la búsqueda de objetivos de inflación.

Las características de este nuevo régimen monetario serían: ${ }^{4}$

- El reconocimiento de la estabilidad de precios como el objetivo fundamental de la política monetaria.

- El anuncio de objetivos de inflación de mediano plazo.

- Contar con una autoridad monetaria autónoma.

- La aplicación de la política monetaria en un marco de transparencia, el cual se sustenta en una estrategia de comunicación respecto de los objetivos, planes y decisiones de la autoridad monetaria.

- Un análisis de todas la fuentes de presiones inflacionarias con el fin de evaluar la trayectoria futura del crecimiento de los precios. Dicho

\footnotetext{
${ }^{2}$ El FMI distingue 4 grandes categorías: hard pegs (incluyendo regímenes de convertibilidad), soft pegs (bandas cambiarias, mini devaluaciones sucesivas o crawling pegs), regímenes flotantes (flotantes y libre flotación) y una categoría residual.

${ }^{3}$ Compra y venta de divisas, por lo general no es considerado como una intervención -fmi - debido a que el diseño de dichos programas minimiza el impacto en el tipo de cambio.

${ }^{4}$ Banco de México. Esquema de Objetivos de Inflación. Disponible en: http://www.banxico. org. $\mathrm{mx} /$ politica-monetaria-e-inflacion/material-de-referencia/intermedio/politica-monetaria/ \{5C9B2F38-D20E-8988-479A-922AFEEBB783\}.pdf
} 
análisis es la principal referencia para las decisiones de la política monetaria.

- El uso de mediciones alternativas de la inflación, como la inflación subyacente, para separar aquellos fenómenos que inciden de manera transitoria sobre la inflación e identificar la tendencia de mediano plazo del crecimiento de los precios.

La primera característica señala la estabilidad de precios como el principal objetivo que persigue la política monetaria, así mismo se señala que se deben identificar las fuentes inflacionarias para ser tomadas como referencia para las decisiones de política, dentro de ellas, es sabido que el tipo de cambio es una de las variables que inciden sobre el nivel de precios, debido al mecanismo de traspaso "pass-through".

Este nuevo régimen monetario se inserta dentro de las políticas conocidas como el Consenso de Washington, John Williamson (2000) señala que existen dos interpretaciones del mismo; por una parte se tiene la del fundamentalismo de mercado y por otra, la del Consenso entendida como un set de políticas necesarias en dicho momento dictadas por Washington.

El fundamentalismo de mercado fue la senda por la que México optó, ya que el proceso de ajuste que vivió la economía, buscaba precisamente, el logro de objetivos de estabilidad más que objetivos de reducción de la pobreza, debido a que se liberalizó la cuenta de capital para lograr la integración económica con los países vecinos, de acuerdo a Williamson (2000), ello debe de estar acompañado de regulación, de otra forma dará paso a "prestamos mal dirigidos y eventualmente a una crisis que llevará a los contribuyentes a pagar las pérdidas de hacer malos préstamos" (p. 258). Continuando con Williamson (2000), las políticas acorde a su trabajo original -en el cual proponía el Consenso como un set de políticas necesarias y dictadas por Washington- era pro pobres, es decir, iban orientadas a la causa de la reducción de la pobreza.

Dentro de ellas encontramos el lograr un tipo de cambio competitivo y ello debe ser más importante que la forma en que éste sea determinado. Menciona Williamson (1990) que "los tipos de cambio deben ser determinados por las fuerzas del mercado, o su conveniencia debe ser juzgada sobre la base si su nivel es consistente con los objetivos macroeconómicos" (p. 13).

Esto último pareciera no ser bien interpretado por las autoridades monetarias en México, y han optado únicamente por buscar que el tipo de 
cambio sea consistente con los equilibrios macroeconómicos, olvidando la preponderancia de la determinación de un tipo de cambio competitivo, pasando lo primero a segundo plano. Dentro del discurso oficial, no existe preocupación alguna por lograr un tipo de cambio competitivo, sino más bien se inclinan por lograr una mayor reducción de los costos salariales, por ejemplo para el caso del Instituto Mexicano para la Competitividad A. C. (2011) se define la competitividad como "la capacidad de los países para atraer y retener inversión y talento” (p. 233).

Ante la búsqueda de equilibrios macroeconómicos, el tipo de cambio dejó de ser una herramienta del gobierno a favor del crecimiento económico, anclándolo a los objetivos de estabilidad que se necesitaban para la reducción de la inflación por medio del abaratamiento de productos importados, para lo que se necesitaba un tipo de cambio peso-dólar apreciado. Se pensaba, que los precios de los productos nacionales se fijarían con base en los productos importados, debido a la competencia que se generaría al abrir el mercado interno al exterior, pero ello terminó por representar una menor competitividad de la producción nacional.

Continuando con Williamson (1990), señala:

\begin{abstract}
la prueba de si el tipo de cambio resalta apropiado, ser consistente en el mediano plazo con los objetivos macroeconómicos. En el caso de las economías en desarrollo, el tipo de cambio real necesita ser suficientemente competitivo para promover una tasa de crecimiento de las exportaciones que permita a la economía crecer a su tasa máxima potencial permitida por el lado de la oferta, manteniendo el déficit de cuenta corriente en un tamaño que pueda ser financiado sobre una base sustentable (p.14).
\end{abstract}

Aclara Williamson (1990) que el tipo de cambio no debe ser más competitivo que ello, debido a que puede llevar a incrementos en el nivel de precios así como limitar los recursos disponibles para la inversión y por tanto del crecimiento del producto (p. 15).

Contrario al planteamiento del banco central, existen diversas posturas que argumentan que la flotación del tipo de cambio está manipulada por lo que no existe una libre flotación del tipo de cambio, tal es el caso de Huerta (2011) mismo que señala que no ha habido cambio alguno en la instrumentación de las políticas económicas que cuando se trabajaba con un régimen de tipo de cambio fijo, menciona "si en realidad existiera un tipo de cambio flexible, y el banco central no interfiriera en el mercado de divisas, el déficit de comercio exterior llevaría a la devaluación de la moneda nacional" (p. 43). 
Señala Huerta (2001) que la liberalización económica impide trabajar con un tipo de cambio flotante "pues daría lugar a prácticas especulativas y fuertes fluctuaciones en la paridad cambiaria que afectarian la rentabilidad de los activos financieros en poder del capital internacional" (p. 17) es por ello que el gobierno orienta la política económica para asegurar la estabilidad del tipo de cambio nominal.

Como menciona Wray (2012) en un régimen de tipo de cambio fijo, el gobierno utiliza la política económica para evitar movimiento en el tipo de cambio, justamente como describe Huerta (2011) para el caso de la economía mexicana la liberalización económica ha venido acompañada de políticas tales como disciplina fiscal, manejo prudencial de la oferta monetaria, altas tasas de interés y privatizaciones, todo ello con miras a mantener el tipo de cambio dentro en ciertos niveles.

En este mismo sentido, Calvo y Reinhart (2002) realizan un estudio empírico de 1989 a 1994 y 1994 a 1999, dentro del cual analizan el comportamiento del tipo de cambio, de las reservas internacionales y de la tasa de interés, para ver si realmente los países que dicen operar bajo un régimen de tipo de cambio flotante, en realidad así opera. Dentro del grupo de países seleccionados ${ }^{5}$ encuentran que México, es uno de los países en los cuales flota más el tipo de cambio con una probabilidad de que el tipo de cambio se mantenga en una banda de mas/menos 2.5 de $63.5 \%$, es decir, existe una probabilidad de $36.5 \%$ que el tipo de cambio fluctúe más de $2.5 \%$ (que son las bandas que establecen los autores) en cualquier mes determinado. Ello comparado con países que se declararon flotantes como Bolivia, Canadá e India que mantuvieron durante el periodo de estudio una probabilidad de mantenerse en dichas bandas en alrededor de 93 por ciento.

Si se observa el periodo anterior a la crisis, el estudio empírico que realizan Calvo y Reinhart (2002) de 1989 a 1994, en el cual se conjugan dos regímenes cambiarios en México (de acuerdo al Banco de México del 1985 a 1991 se trabajó bajo flotación regulada y de 1991 a 1994 por medio de bandas cambiarias) se obtuvo $95.7 \%$ de probabilidad que el tipo de cambio no fluctuara más allá de una banda de mas/menos $2.5 \%$, visto de otra forma, existía solo $4.3 \%$ de probabilidad que el tipo de cambio fluctuara más allá del mas/menos 2.5 por ciento.

Para tales periodos también se realiza el análisis de las variaciones en las reservas internacionales, mostrándose como resultado de 1989 a 1994

${ }^{5}$ El estudio abarca países con regímenes de tipo de cambio flotante como Australia, Canadá, Japón, Estados Unidos para diversos periodos que van desde 1970 hasta 1999. 
de $39.9 \%$ de probabilidad que fluctúe dentro de la banda de mas/menos $2.5 \%$, mientras que para el periodo de 1994 a 1999 es de $28.3 \%$, lo que nos indica, una alta probabilidad para los dos periodos de variaciones más allá del mas/menos $2.5 \%$ para dichos periodos, otorgando indicios de fuertes movimientos de las reservas internacionales.

De lo anterior se desprende cómo la variación de las reservas internacionales en México durante dicho periodo de estudio es grande, siendo un país que deja flotar su moneda. Recordando lo que dice la literatura monetaria, bajo un régimen de tipo de cambio flotante las variaciones en las reservas internacionales deben de ser iguales a cero. Ello debido a que las autoridades no intervienen en el mercado de divisas. Entonces ¿por qué se observó una fuerte variación de las reservas internacionales?

El Banco de México sostiene que las reservas internacionales son de fuerte importancia debido a su impacto sobre el mercado cambiario ante un escenario de fuerte volatilidad, el principal problema aquí radica en que es mayor la necesidad de mantener un fuerte monto de reservas internacionales para las economías que trabajan con regímenes de tipo de cambio fijos y no para los que trabajan bajo un régimen de tipo de cambio flotante, puesto que las primeras comprometen el tipo de cambio a cierto nivel por unidades de moneda extranjera.

Argumentan que las reservas internacionales reflejan la 'fortaleza de la economia', contribuyen para hacer frente a las obligaciones de pago del gobierno, al igual que el nivel adecuado de reservas está en función de la coyuntura económica del país considerando el costo-beneficio de mantenerlas. El Banco de México ${ }^{6}$ sostiene que "el objetivo de contar con una reserva internacional es el de contribuir a la estabilidad de precios mediante la compensación de desequilibrios en la balanza de pagos" lo cual va de acuerdo al mandato del Banco Central, objetivo único que persigue la política monetaria, pero ello no es congruente con un régimen de tipo de cambio flexible, ya que el hecho de que se busque mantener reservas internacionales para contribuir a la estabilidad de precios implica la intervención de las autoridades dentro del mercado de divisas, no dejando flotar realmente al tipo de cambio, buscando mantener el tipo de cambio en ciertos niveles.

Señala además el Banco de México “así, las reservas internacionales fungen como un seguro para afrontar contingencias que podrían reflejarse en una disminución de los flujos comerciales o de capital de la balanza de pagos, generados principalmente por desequilibrios macroeconómicos y

${ }^{6}$ Banco de México. Sistema Financiero. Disponible en: http://www.banxico.org.mx/divulgacion/sistema-financiero/sistema-financiero.html\#niveladecuadodereservasinternacionales. 
financieros, ya sean de origen interno o externo". Todo lo anterior refleja, que en realidad no se trabaja con un tipo de cambio de libre flotación como sostienen las autoridades, ya que de encontrarse en condiciones adversas, se opta por intervenir en el mercado cambiario, olvidándose de que una de las ventajas de la flotación del tipo de cambio es que ésta absorbe los efectos de los choques externos al depreciarse la moneda.

Para dar respuesta a la pregunta inicial de si se trabaja bajo un régimen de tipo de cambio flotante o semi-fijo, se replican las medidas de volatilidad que hacen Calvo y Reinhart (2002) utilizando: cambios porcentuales mensuales de las variables tipo de cambio nominal, reservas internacionales y tasa de interés nominal, que se denotan como, $\Delta \mathrm{F} / \mathrm{F}$ (donde $\Delta \mathrm{F}=\mathrm{F}_{\mathrm{t}}-\mathrm{F}_{\mathrm{t}-1}$ ), $\Delta \mathrm{i}$ $\left(\Delta \mathrm{i}: \mathrm{i}_{\mathrm{t}}-\mathrm{i}_{\mathrm{t}-\mathrm{1}}\right.$ ) (tipo de cambio, cambio en las reservas internacionales y cambio en la tasa de interés respectivamente). Considerando $\mathrm{x}^{\mathrm{c}}$ como la banda que toma los valores de 2.5 y $5 \%$. Únicamente para el caso de México de diciembre de 1994 a diciembre de 2012, periodo declarado como de libre flotación del tipo de cambio.

Cuando $\mathrm{x}=$, es decir $\mathrm{x}$ toma el valor del tipo de cambio nominal se observa lo siguiente:

$$
\mathrm{P}\left(\mathrm{x}<\mathrm{x}^{\mathrm{c}} \text { Fijo }\right)>\mathrm{P}\left(\mathrm{x}<\mathrm{x}^{\mathrm{c}} \text { Flotante }\right)
$$

Esto es la probabilidad de que el tipo de cambio sea menor que el ancho de banda, dado que el tipo de cambio permanece fijo es mayor a la probabilidad de que el tipo de cambio sea menor que el ancho de banda para un tipo de cambio flotante. Por lo que será menor la probabilidad para una economía que trabaja con un tipo de cambio flotante.

Ello se debe de acuerdo a Calvo y Reinhart (2002) a que los choques en la demanda de dinero y las expectativas al trabajar bajo un régimen de tipo de cambio fijo, se acomodan por medio de compras y ventas de reservas de divisas.

Cuando $\mathrm{X}=\Delta \mathrm{F} / \mathrm{F}$, se observa el caso contrario.

$$
\mathrm{P}\left(\mathrm{x}<\mathrm{x}^{\mathrm{c}} \text { Fijo }\right)<\mathrm{P}\left(\mathrm{x}<\mathrm{x}^{\mathrm{c}} \text { Flotante }\right)
$$

La probabilidad de que el cambio en las reservas caiga dentro de la banda $\mathrm{x}^{\mathrm{c}}$ es una función decreciente del grado de rigidez del tipo de cambio, debido a que los choques en la demanda de dinero y cambios en expectativas se acomodan para prevenir variaciones en el tipo de cambio (Calvo y Reinhart, 2002). 


\section{Cuadro 1}

Volatilidad de indicadores seleccionados

\begin{tabular}{|c|c|c|c|c|c|c|}
\hline & & $\begin{array}{r}\text { DeI } \\
\text { de una bau }\end{array}$ & $\begin{array}{l}\text { tro } \\
\text { da } \pm 2.5 \%\end{array}$ & $\begin{array}{r}\text { De } \\
\text { de una ba }\end{array}$ & $\begin{array}{l}\text { atro } \\
\text { nda } \pm 5 \%\end{array}$ & Mayor que $\pm 4 \%$ \\
\hline País & Periodo & $\begin{array}{c}\text { Tipo de } \\
\text { Cambio } \\
\text { Nominal }\end{array}$ & Reservas & $\begin{array}{l}\text { Tipo de } \\
\text { Cambio } \\
\text { Nominal }\end{array}$ & Reservas & $\begin{array}{c}\text { Tasa de } \\
\text { Interés } \\
\text { Nominal }\end{array}$ \\
\hline México & $\begin{array}{l}\text { Diciembre } 1994- \\
\text { Diciembre } 2012\end{array}$ & 47.0 & 5.0 & 79.1 & 10.0 & 65.4 \\
\hline México* & $\begin{array}{l}\text { Octubre } 2008- \\
\text { Noviembre } 2011\end{array}$ & 61.5 & 6.0 & 91.8 & 90.6 & 100 \\
\hline
\end{tabular}

Nota: *Periodo pos-crisis.

Fuente: Instituto Nacional de Estadística y Geografía, Organización para la Cooperación y el Desarrollo Económico y Banco de México.

Nota: *Para México se utilizan los Certificados de la Tesorería a 28 días y para Estados Unidos la Tasa de Fondos Federales (efectiva), las tasas de interés corresponden al mes de enero de cada año.

Fuente: Instituto Nacional de Estadística y Geografía y Banco de México.

Se trabaja bajo la misma banda comparativa que utiliza Calvo y Reinhart (2002), y se añade el cálculo de una banda de mas/menos 5\%, lo que permite calcular bajo un intervalo de $90 \%$ de confianza. De los resultados anteriores se desprende que la probabilidad de que el tipo de cambio se mantenga dentro de las bandas de mas/menos $2.5 \%$ es de $47 \%$, mientras que la probabilidad de que el tipo de cambio flote más de $2.5 \%$ es de $53 \%$ en algún mes dado, por lo que se tiene un resultado casi de 50\% que el tipo de cambio se mantenga dentro de las bandas o que vaya más allá.

Si se observa el apartado de las reservas internacionales, se tiene evidencia empírica que en dicho periodo existen fuertes variaciones en el monto de reservas, ello debido a que la probabilidad que las reservas se mantengan dentro del rango mencionado es muy baja, existe $95 \%$ de probabilidad que las reservas varíen más allá del mas/menos $2.5 \%$. Cabe recalcar que esta probabilidad de que se mantenga dentro de las bandas es menor a la que documenta Calvo y Reinhart (2002) por lo que al ampliar el periodo de estudio, aumenta la probabilidad que el tipo de cambio flote, así como se incrementa la probabilidad de la variación de las reservas internacionales.

La probabilidad que el tipo de cambio fluctúe dentro de un intervalo de mas/menos 5, se observa que incrementa la probabilidad de que el tipo de cambio se mueva dentro de las bandas, por el lado de las reservas, se ob- 
serva que se mantiene la fuerte probabilidad de las variaciones durante el periodo de estudio.

Comparando los resultados que se obtienen bajo las bandas de $2.5 \mathrm{y}$ $5 \%$, en cuanto al tipo de cambio y reservas internacionales, se observa un incremento en la probabilidad de que se mantenga dentro de las bandas al analizarse bajo bandas de 5\%, se puede concluir que el tipo de cambio flota derivado de ambos resultados, lo que llama la atención, son las fuertes variaciones mes por mes en las reservas internacionales, bajo bandas de 2.5 y $5 \%$, ya que los datos indican oscilaciones más allá de dichos intervalos.

Es de importancia el análisis del movimiento en las reservas internacionales, puesto que se utilizan para mitigar fuertes fluctuaciones en el tipo de cambio, si bien en teoría, el cambio en las reservas debe de ser cero bajo un régimen de tipo de cambio flotante, Calvo y Reinhart (2002) sostienen que esto no es tan sencillo sino que éstas pueden variar debido a fluctuaciones en la valoración de los activos y los intereses devengados. Así también como "transacciones ocultas de reservas en moneda extranjera (...) en ausencia de ellas (transacciones ocultas de reservas) los países descansan fuertemente en operaciones de mercado abierto y cambios en la tasa de interés para limitar el tipo de cambio" (p. 388). En el primer caso las líneas de crédito pueden ser usadas para defender el tipo de cambio al existir presiones especulativas, como fue la "linea swap" establecida con la Reserva Federal de Estados Unidos, en octubre de 2008 que estaría vigente hasta octubre de 2009, ya que fue una medida precautoria que adoptó el Banco de México.

De los resultados emanados de las variaciones en las reservas internacionales. se observa que en contra de lo establecido $\mathrm{P}\left(\mathrm{x}<\mathrm{x}^{\mathrm{c}}\right.$ Fijo $)<\mathrm{P}\left(\mathrm{x}<\mathrm{x}^{\mathrm{c}}\right.$ Flotante), la probabilidad de que las variaciones en las reservas internacionales caiga dentro de $\mathrm{x}^{\mathrm{c}}$ es una función decreciente de la rigidez del tipo de cambio, esto es, que la probabilidad de que las variaciones en las reservas caiga dentro de las bandas va decreciendo a medida que aumenta la rigidez del tipo de cambio. Ello debido a que se observan fuertes oscilaciones mes por mes con bandas de 2.5 y $5 \%$ y una relativa flotación del tipo de cambio. Esto es consistente ante una fuerte intervención de las autoridades en el mercado de divisas, lo cual en teoría, no debería de suceder en un régimen cambiario de libre flotación; por lo que las reservas oscilan fuertemente mes por mes para así asegurar un tipo de cambio más estable.

La variación de la tasa de interés se incorpora al análisis, ya que dicho movimiento permite conocer si el banco central está utilizando activamente la política monetaria como una forma de estabilizar el tipo de cambio. De 
acuerdo a Calvo y Reinhart (2002), la tasa de interés puede variar también "si la expectativa sobre inflación futura o los tipos de cambio permanecen anclados, así como en caso que las autoridades carezcan de credibilidad” (p. 384).

Además de ello, la tasa de interés puede ser fijada de acuerdo a objetivos nacionales, como se tocará más adelante, la tasa de interés en México se fija de acuerdo a los objetivos implícitos de estabilizar el tipo de cambio, por lo que las autoridades se ven obligadas a fijar la tasa de interés por encima de la tasa de interés internacional para atraer capitales. Por ello se realiza el cálculo considerando una banda de 4\%, para la tasa de interés nominal en México, en el cuadro se observa que la probabilidad que la tasa de interés cambie por 400 puntos base (4\%) o por encima de ello, en cualquier mes dado, para el caso de México durante el periodo de estudio, es de 65.4\%. Esto es una probabilidad demasiado alta, lo que permite señalar que las autoridades utilizan altas tasa de interés como una vía para evitar presiones sobre el tipo de cambio.

Respecto a lo anterior dicen Calvo y Reinhart (2002) que "la volatilidad de la tasa de interés no es resultado de la adhesión a objetivos monetarios rígidos para hacer frente a choques de demanda de dinero fuertes y largos. En realidad, la mayoría de los países no cuentan con reglas implícitas o explícitas de oferta de dinero" (p. 392). Es por ello que los autores concluyen que los cambios en la tasa de interés son producto de un intento de estabilizar el tipo de cambio junto con las operaciones de mercado abierto y la falta de credibilidad.

De los resultados anteriores se desprende que, si bien el tipo de cambio ha flotado, se puede hablar de una flotación sucia o manejada, utilizando como herramienta para mantener el tipo de cambio estable las reservas internacionales y la tasa de interés. No se observan las características de un régimen de libre flotación como el Banco de México afirma, en cambio se observan factores que permiten afirmar que no se deja flotar libremente el tipo de cambio, sino que el movimiento en tasa de interés y las fuertes oscilaciones en reservas internacionales permiten sostener que mediante dichos mecanismos se logra minimizar la flotación o volatilidad del tipo de cambio.

Periodo pos crisis: como dato adicional, se calculan las volatilidades para el periodo de octubre de 2008 a noviembre de 2011 , fecha de inicio de la crisis financiera internacional y fecha en la cual culmina la intervención en el mercado de divisas por parte del Banco de México. Se observa un incremento de la probabilidad de que el tipo de cambio permanezca dentro 
de las bandas, bajo una banda de mas/menos $2.5 \%$, la probabilidad es de $61.5 \%$, mientras que bajo una banda de mas/menos $5 \%$ la probabilidad es aún mayor -91.8\%-, concluyendo de ambos resultados, que el tipo de cambio nominal flota en menor medida, o se mantiene estable.

Por el lado de las reservas internacionales, se tiene una probabilidad del $60 \%$ de que se mantenga dentro de bandas del mas/menos 2.5 y $90.6 \%$ que se mantenga bajo bandas del mas/menos $5 \%$. Mientras que una probabilidad de $100 \%$ de que la tasa de interés nominal se mueva más allá de 4\%. ¿Qué dice todo esto? Si bien el tipo de cambio se mantuvo relativamente estable, fue gracias al fuerte manejo de la tasa de interés nominal que permitió una mayor atracción de capitales, que a su vez permitió configurar un escenario de fortaleza en las reservas internacionales, alcanzando máximos históricos, por lo que no se observan bruscos movimientos, para este periodo de estudio.

\section{El tipo de cambio como herramienta anti-inflacionaria}

Una vez que 'colapsó' la estrategia de política monetaria que consideraba al tipo de cambio como ancla nominal de la economía ante la crisis de 1994, el Banco de México decidió orientar su estrategia hacia un nuevo marco de política monetaria basado en metas de inflación, que comenzaría a operar en 1999, basado en la regla de Taylor, el cual buscaría controlar la inflación por medio de la tasa de interés.

En este apartado se busca demostrar, cómo en realidad el tipo de cambio sigue generando presiones sobre precios y por ello el banco central continúa con una estrategia similar a la que operaba antes de 1994, considerando al tipo de cambio como ancla nominal, principalmente porque ha impedido la libre flotación del tipo de cambio, por lo que más bien se ha observado un régimen de tipo de cambio semi-flotante o de flotación sucia en la búsqueda de la estabilidad de precios.

Existen múltiples razones del por qué una economía luchará por mantener su tipo de cambio estable, tales como el acceso a los mercados de capitales y dolarización de los pasivos, entre otros. En el presente trabajo se adopta el modelo presentado por Calvo y Reinhart (2002) que sostienen que el miedo a flotar proviene de una combinación de la falta de credibilidad (manifestado en las primas de riesgo), un alto traspaso -del tipo de cambio a precios- y objetivos de inflación. Este modelo describe las principales características del temor a flotar de las autoridades que dictan la política cam- 
biaria en México, por ello que se considera el adecuado para el desarrollo del presente apartado.

Perrotini (2007) cita a Ball (1999) y Svesson $(2000,2007)$ quienes sostienen que la adopción de la regla de Taylor implica trabajar con un régimen de tipo de cambio flexible, ya que éste no jugaría un papel importante en la búsqueda de un objetivo de inflación, por ello que sostiene Haldane (1995) que el tipo de cambio no es utilizado para perseguir el objetivo de estabilidad de precios (p. 41).

Planteamientos como el de Baqueiro, et al (2003) sostienen que una de las críticas que se realizan a lo regímenes de libre flotación es principalmente, que no generan los beneficios que en teoría deberían de tener. Ello se debe al escenario de inflación en el que la economía se encuentre, es decir, si la economía atraviesa escenarios altos de inflación, el traspaso de tipo de cambio a precios será alto, pero de consolidarse bajos niveles de inflación en una economía, el efecto traspaso disminuirá. Por lo que concluyen que "para gozar de los beneficios de la libre flotación es necesario alcanzar inflaciones bajas y estables" (p. 9). Esto último se lograría-de acuerdo a sus argumentos- por medio de la utilización de la tasa de interés para disminuir la brecha de inflación.

De acuerdo a Taylor (2000) se disminuye la intensidad del traspaso del tipo de cambio a precios a medida que la inflación disminuye, ello se debe a que las empresas no transmiten los choques en sus costos hacia los consumidores, al disminuir el poder de la empresas en la determinación de sus precios. Es por ello que se adopta el esquema de objetivos de inflación para poder debilitar el traspaso del tipo de cambio sobre precios (Baqueiro, et al, 2003).

Los anteriores autores consideran a la inflación como un fenómeno monetario -debido a desajustes entre oferta y demanda monetaria- y no consideran que la economía mexicana experimente un proceso de inflación estructural como sucede en gran parte de las economías latinoamericanas. Olivera (2012) explica que de acuerdo a la posición estructuralista la inflación se debe a desajustes sectoriales que influyen sobre ciertos productos. "La insuficiencia de oferta de tales productos se traduce por alzas de precios individuales, que luego se generalizan por su influencia sobre el costo de producción de otros bienes o por su relación con el costo del nivel de vida y con la tasa real de salarios" (p. 149).

Junto con lo anterior, la economía mexicana, dada sus características, es considerada como precio aceptante de los precios internacionales. Es por ello, que por la vía del tipo de cambio nominal se pueden afectar los precios 
internos de los bienes y servicios, fenómeno conocido como el mecanismo de traspaso (pass-through).

Aunque diversos estudios argumenten que existe evidencia que el efecto de las fluctuaciones del tipo de cambio sobre precios se haya reducido desde la adopción del esquema de objetivos de inflación, existen planteamientos en los cuales se afirma que el tipo de cambio actúa como ancla de la inflación en contraposición de los planteamientos de la autoridades que sostienen que la política monetaria es en ancla nominal de la economía. ${ }^{7}$

En esta sintonía, Perrotini (2007) argumenta que para el caso de una economía pequeña y abierta como lo es la mexicana, el tipo de cambio "persiste como ancla de la inflación en el marco de la regla de Taylor incluso en el largo plazo". Señala más adelante "el problema es de carácter estructural: con la liberalización comercial aumentó el coeficiente del contenido de insumos importados de nuestras exportaciones, y el coeficiente de traspaso (pass-through) del tipo de cambio a los precios continúa siendo significativo, por lo que una devaluación monetaria real tiene el efecto de un choque de oferta" (p. 48).

En el análisis de Huerta (2004) se considera el alto componente importado de la demanda nacional al igual que Perrotini (2007), indicando que "el gobierno se ve más obligado a que la moneda nacional sea aceptada y no haya un reclamo de divisas por quienes nos venden tales bienes" (p. 2) ello, obliga a la economía nacional a crear alternativas de inversión en moneda nacional con el fin de evitar presiones sobre el tipo de cambio.

Se ha trabajado como si se estuviese bajo un régimen de tipo de cambio fijo ya que la política fiscal y monetaria se acomoda para mantener en ciertos niveles el tipo de cambio nominal. Ello es necesario ante el actual contexto de liberalización económica en el que México se encuentra inmerso para el logro de tales objetivos. De acuerdo a Huerta (2001) un tipo de cambio estable es una condición necesaria para que éste sea rentable y así los capitales fluyan hacia la economía mexicana, y permita conservar el valor del monto invertido, por lo que un tipo de cambio "semij fijo" es un compromiso obligado para nuestra economía.

No obstante lo anterior, el problema que acompaña a un tipo de cambio nominal estable, es que se imposibilita que este sea una herramienta más de política comercial a favor de la competitividad, así como del sector productivo, que permita una mejora en la balanza comercial.

Como se analiza en el apartado anterior, la tasa de interés ha jugado un

${ }^{7}$ Se refiere al medio para controlar el nivel de precios y estabilizar la producción económica. 
papel importante en la determinación del tipo de cambio. Al respecto Huerta (2006) sostiene "la política monetaria de los 'cortos' [...] restringe el crecimiento de la liquidez deseada por la economía, por lo que mantiene una relativa alta tasa de interés (en función de la inflación y la tasa de interés de Estados Unidos)". Son las políticas tales como la de restricción de la oferta monetaria las que coadyuvan de forma indirecta a minimizar las fluctuaciones del tipo de cambio nominal, ya que permiten mantener en niveles deseados las tasas de interés. Lo anterior en contraposición a una de las ventajas del régimen de tipo de cambio flotante, ya que se argumenta que la política monetaria no se restringe a cierto nivel de tipo de cambio lo que permite determinar libremente las tasas de interés para alcanzar un equilibrio interno (Baqueiro, et al, 2003).

Como se puede observar en la gráfica 1, si se compara la tasa de interés de nuestro país con la de nuestro principal socio comercial -Estados Unidos- se observa de 1994 a 2012 un fuerte diferencial de las tasas de interés, disminuyendo la brecha a comienzo de los años 2000, pero existiendo aún una fuerte diferencia.

\section{Gráfica 1}

América Latina 2000-2011 grupo III: tasa de crecimiento real anual del PIB percápita

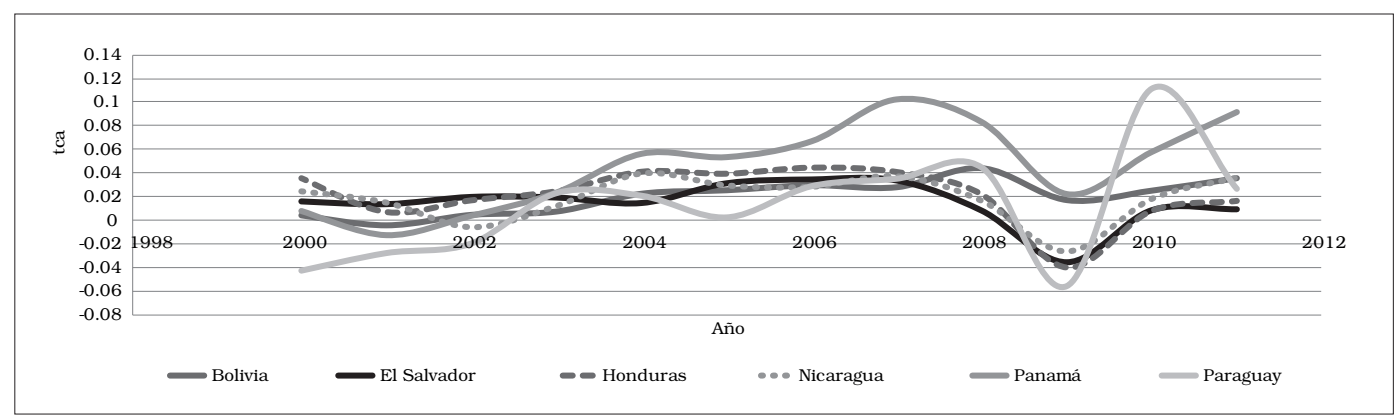

De acuerdo a Huerta (2006) las altas tasas de interés funcionan para que los flujos de capital no actúen de forma especulativa, así también como para frenar la actividad económica, con ello evitando presiones sobre el déficit de comercio exterior, por la vía de atraer capitales a la economía y así evitar presiones sobre el tipo de cambio (p. 12). Las altas tasas de interés, son producto de la necesidad de financiar el déficit de comercio exterior por medio de mantener un superávit en la cuenta de capital. 
Existen también posturas como la de Esquivel (2010) que únicamente ven el movimiento de la tasa de interés como respuesta al movimiento en el nivel de precios, pero sin olvidar la incidencia sobre el tipo de cambio y las reservas internacionales. Sostiene que el banco central actúa de forma predecible ya que de acuerdo a la coyuntura económica en la que se encuentre reacciona con un alza en su principal instrumento que es la tasa de interés. Es por ello que argumenta que la conducción de la política monetaria se puede explicar por medio de la regla de Taylor $^{8}$ (p. 64).

Como se observa de las dos posturas anteriores el banco central ha hecho uso de la tasa de interés tanto para minimizar las fluctuaciones sobre el tipo de cambio que a su vez permite evitar presiones sobre precios. Pareciera que la postura de Esquivel (2010) pasara el tipo de cambio a segundo plano, siendo ésta una variable importante para la determinación de los precios internos dado que es una economía abierta. Mientras que con Huerta (2006) el papel de las tasas de interés está en función de reducir la inflación mediante la estabilidad del tipo de cambio.

Sin embargo, las altas tasas de interés han permitido la apreciación del tipo de cambio a través de la atracción de capitales, ya que nuestra economía termina por ofrecer tasas de retorno mayores que en el resto del mundo. ${ }^{9}$ La apreciación del tipo de cambio que ha sido producto de ello, termina por generar asimetrías en la rentabilidad de la inversión, de acuerdo a Perrotini (2007) las asimetrías son proporcionales a la apreciación monetaria, pues los extranjeros obtienen una tasa de retorno real mayor a los inversionistas nacionales (p. 3), lo anterior bajo el supuesto que ambos compren bonos nacionales.

El tipo de cambio continúa jugando un papel importante como ancla nominal de la inflación, como lo hizo en el esquema monetario que precedió a 1994. Mediante el uso de la tasa de interés como factor clave para la atracción de capitales hacia la economía nacional, ha traído consigo una apreciación la moneda nacional. A su vez se observa cómo la estrategia de la regla de Taylor no ha sido compatible con un régimen de tipo de cambio flotante, como concluye Perrotini (2007) contrario a lo que establecen Ball (1999) y Svesson $(2000,2007)$.

\footnotetext{
${ }^{8}$ De acuerdo a Esquivel (2010) Taylor sostiene que "el banco central debería de aumentar la tasa de interés de forma más que proporcional con los aumentos en la inflación para poder aumentar la tasa de interés real y así reducir las presiones inflacionarias" (p. 49).

${ }^{9} \mathrm{Si}$ se comparasen con las tasas de interés en los mercados internacionales.
} 


\section{Medición de desalineamiento del peso frente al dólar}

En la presente investigación se utiliza la hipótesis de la Paridad del Poder de Compra (PPC) la cual señala de acuerdo a Guerrero, et al (2007) "el tipo de cambio nominal $\mathrm{E}_{\mathrm{N}}$ es meramente un operador que traduce de manera aproximada el índice de precios externos $\mathrm{P}^{*}$ en términos del índice de precios locales P” (p. 156). El tipo de cambio teórico que debería prevalecer se basa entonces, bajo la premisa que dos países comercializan diversos productos por lo que se utilizan los índices de precios de cada economía y no el de un sólo bien.

Lo anterior se representa en la siguiente ecuación:

$$
\mathrm{E}_{\mathrm{N}} \approx \mathrm{P} / \mathrm{P}^{*} \quad[3]
$$

Conviene realizar el desarrollo para el conocer el origen del cálculo del tipo de cambio teórico por ello si se cumple la PPC el tipo de cambio nominal debería ser igual al tipo de cambio real (e), esto es:

$$
\mathrm{E}_{\mathrm{N}}=\mathrm{e}
$$

Si se sustituye [3] en [4] resultaría igual:

$$
\mathrm{e} \approx \mathrm{P} / \mathrm{P}^{*}
$$

Una vez que se conoce dicha identidad, para el cálculo del tipo de cambio teórico, se necesita tomar un valor de equilibrio de tipo de cambio, en este trabajo se toma como base 1996, principalmente aunque se hace un experimento al variar los valores de equilibrio, a dicho valor de equilibrio se le denomina como $\mathrm{E}^{\mathrm{b}}$.

Se tiene entonces que obtener el tipo de cambio teórico por medio de la siguiente fórmula:

$$
\mathrm{e} \approx \mathrm{E}^{\mathrm{b}}\left(\mathrm{P} / \mathrm{P}^{*}\right) \quad[6]
$$

Con base la ecuación [6] se realiza el cálculo, tomando como base el año de 1996 = 100 para obtener el tipo de cambio teórico, ${ }^{10}$ lo que permitirá conocer el desalineamiento del peso frente al dólar y así conocer posibles indicios

${ }^{10}$ Es el tipo de cambio nominal de un año determinado considerado como referencia, multiplicado por la relación de precios de Estados Unidos y México. 
de una sobrevaluación de la moneda. Se habla de sobrevaluación cuando la diferencia entre el tipo de cambio nominal y el tipo de cambio teórico es positiva, lo que implica que los productos nacionales se vuelven más caros en comparación con los del exterior, lo que trae consigo un deterioro en la balanza comercial.

El ejercicio se muestra el cuadro 2. Consiste en la homogeneización de los índices de precios a base 1996 utilizando el tipo de cambio nominal de ese mismo año como base para multiplicar el coeficiente que resulta de dividir los precios locales $(\mathrm{P})$ entre los precios externos $\left(\mathrm{P}^{*}\right)$, en este caso los precios de Estados Unidos, obteniendo así el tipo de cambio teórico basado sobre la hipótesis del PPC.

Cabe aclarar que se toma como base el tipo de cambio de 1996 ya que en ese año se registra un superávit de comercio exterior en México, al igual que de acuerdo a Guerrero et al. (2007) hubo un fuerte sobre ajuste de la moneda en 1995.

\section{Cuadro 2}

\section{Apreciación del peso mexicano frente al dólar y evolución de precios relativos, 1996-2012}

\begin{tabular}{|c|c|c|c|c|c|c|}
\hline Año & $\begin{array}{c}\text { INPC México (Base } \\
\text { 1996=100) (1) }\end{array}$ & \begin{tabular}{|l} 
INPC Estados Unidos \\
(Base 1996=100) (2)
\end{tabular} & $\begin{array}{l}\text { México/Estados } \\
\text { Unidos (1)/(2) }\end{array}$ & $\begin{array}{c}\text { Tipo de cambio } \\
\text { nominal }\end{array}$ & $\begin{array}{c}\text { Tipo de Cambio } \\
\text { Teórico }^{1}\end{array}$ & Apreciación $^{2}$ \\
\hline 1996 & 100.00 & 100.00 & 1.00 & 7.60 & 7.60 & 0.00 \\
\hline 1997 & 120.63 & 102.34 & 1.18 & 7.92 & 8.96 & 13.12 \\
\hline 1998 & 139.84 & 103.93 & 1.35 & 9.14 & 10.23 & 11.93 \\
\hline 1999 & 163.03 & 106.20 & 1.54 & 9.56 & 11.67 & 22.02 \\
\hline 2000 & 178.51 & 109.79 & 1.63 & 9.46 & 12.36 & 30.68 \\
\hline 2001 & 189.87 & 112.89 & 1.68 & 9.34 & 12.78 & 36.81 \\
\hline 2002 & 199.43 & 114.68 & 1.74 & 9.66 & 13.22 & 36.86 \\
\hline 2003 & 208.49 & 117.28 & 1.78 & 10.79 & 13.51 & 25.22 \\
\hline 2004 & 218.27 & 120.42 & 1.81 & 11.29 & 13.77 & 22.05 \\
\hline 2005 & 226.97 & 124.51 & 1.82 & 10.90 & 13.85 & 27.12 \\
\hline 2006 & 235.21 & 128.53 & 1.83 & 10.90 & 13.91 & 27.60 \\
\hline 2007 & 244.54 & 132.19 & 1.85 & 10.93 & 14.06 & 28.64 \\
\hline 2008 & 257.07 & 137.27 & 1.87 & 11.13 & 14.23 & 27.88 \\
\hline 2009 & 270.69 & 136.78 & 1.98 & 13.51 & 15.04 & 11.29 \\
\hline 2010 & 281.94 & 139.02 & 2.03 & 12.64 & 15.41 & 21.97 \\
\hline 2011 & 291.55 & 143.41 & 2.03 & 12.43 & 15.45 & 24.29 \\
\hline 2012 & 303.54 & 146.38 & 2.07 & 13.17 & 15.76 & 19.66 \\
\hline
\end{tabular}

${ }^{1}$ Tipo de cambio teórico.- Es el tipo de cambio nominal de un año determinado (1996) consderado como referencia, multiplicado por la relación de precios de Estados Unidos y México.

${ }^{2}$ Apreciación.- Es la diferencia porcentual entre el tipo de cambio nominal y el tipo de cambio teórico. 
De acuerdo a Guerrero, et al. (2007) la relación de largo plazo no es válida en horizontes cortos debido a que existen bienes que se producen en un determinado país que no son comerciables, las variaciones de los precios internos y externos puede ser diferente entre países así como las variaciones en los términos netos de intercambio pueden deberse a razones de oferta y demanda.

En su trabajo dan por sentada la validez de largo plazo de la hipótesis del PPC para la economía mexicana por medio de un ejercicio empírico para un periodo de 1932 a 2005, donde observan que el tipo de cambio nominal no refleja el diferencial del índice de precios, pero no se aleja de dicho diferencial, por lo que observan una relación de equilibrio en el largo plazo con desviaciones en el corto plazo (Guerrero, et al, 2007).

En el cuadro 2 se puede observar una constante apreciación del tipo de cambio nominal de lo que va de 1996 a 2012, prueba de ello es que se observa para finales del periodo el tipo de cambio teórico resulta de 15.76 cuando actualmente es de 13.17 pesos por dólar. Se observa en la gráfica las fuertes disparidades entre el tipo de cambio nominal y el tipo de cambio ajustado en el diferencia por el diferencial de precios.

\section{Tabla 3}

\section{Tipo de cambio teórico: diferentes bases}

\begin{tabular}{|c|c|c|c|c|c|c|c|c|c|c|c|c|c|c|c|c|c|}
\hline Año & $\mathrm{E}$ & & & & ipo de & camb & Dio ajı & istado & al dif & ferenc & ial de $p$ & recios & 1996 & -2012 & & & \\
\hline 1996 & 7.6 & 7.6 & & & & & & & & & & & & & & & \\
\hline 1997 & 7.9 & 9.0 & 7.9 & & & & & & & & & & & & & & \\
\hline 1998 & 9.1 & 10.2 & 9.0 & 9.1 & & & & & & & & & & & & & \\
\hline 1999 & 9.6 & 11.7 & 10.3 & 10.4 & 9.6 & & & & & & & & & & & & \\
\hline 2000 & 9.5 & 12.4 & 10.9 & 11.0 & 10.1 & 9.5 & & & & & & & & & & & \\
\hline 2001 & 9.3 & 12.8 & 11.3 & 11.4 & 10.5 & 9.8 & 9.3 & & & & & & & & & & \\
\hline 2002 & 9.7 & 13.2 & 11.7 & 11.8 & 10.8 & 10.1 & 9.7 & 9.7 & & & & & & & & & \\
\hline 2003 & 10.8 & 13.5 & 12 & 12.1 & 11.1 & 10.3 & 9.9 & 9.9 & 10.8 & & & & & & & & \\
\hline 2004 & 11.3 & 13.8 & 12.2 & 12.3 & 11.3 & 10.5 & 10.1 & 10.1 & 11.0 & 11.3 & & & & & & & \\
\hline 2005 & 10.9 & 13.9 & 12.3 & 12.4 & 11.4 & 10.6 & 10.1 & 10.1 & 11.1 & 11.4 & 10.9 & & & & & & \\
\hline 2006 & 10.9 & 13.9 & 12 & 12 & 11.4 & 10.6 & 10 & 10.2 & 11.1 & 11.4 & 10.9 & 10.9 & & & & & \\
\hline 2007 & 10.9 & 14.1 & 12.4 & 12.6 & 11.5 & 10.8 & 10.3 & 10.3 & 11.2 & 11.5 & 11.06 & 11.0 & 10.9 & & & & \\
\hline 2008 & 11.1 & 14.2 & 12.6 & 12.7 & 11.7 & 11 & 10.4 & 10.4 & 11.4 & 11.7 & 11.20 & 11.2 & 11.1 & 11.1 & & & \\
\hline 2009 & 13.5 & 15.0 & 13.3 & 13.4 & 12.3 & 11.5 & 11.0 & 11.0 & 12.0 & 12.3 & 11.83 & 11.8 & 11.7 & 11.8 & 13.5 & & \\
\hline 2010 & 12.6 & 15 & 13.6 & 13.8 & 12.6 & 12 & 11.3 & 11.3 & 12.3 & 12.6 & 12.12 & 12.1 & 12.0 & 12 & 13.9 & 12.6 & \\
\hline 2011 & 12.4 & 15.5 & 13.7 & 13.8 & 12.7 & 11.8 & 11.3 & 11.3 & 12.3 & 12.7 & 12.15 & 12.1 & 12.0 & 12.1 & 13.9 & 12.7 & 12.4 \\
\hline 2012 & 13.2 & 15.8 & 13.9 & 14 & 12.9 & 12.1 & 11.5 & 11.5 & 12.6 & 12.9 & 12.40 & 12.4 & 12.3 & 12.3 & 14 & 12.9 & 12.7 \\
\hline
\end{tabular}


Del cuadro 3 se deduce que existe evidencia de una sobrevaluación del peso mexicano bajo la hipótesis del PPC, no obstante se hace variar la base, se demuestra una creciente apreciación del peso mexicano frente al dólar. Por ejemplo de tomarse como base 1997 el tipo de cambio ajustado para 2012 sería de 15.8 y no de 13.2 como es el valor del mercado, si se tomase como base 1998 el tipo de cambio debería ser de 14 pesos. Por lo que se concluye que gran parte de la información en la tabla 3, presenta evidencia de la propensión a la sobrevaluación del peso mexicano a su vez que permite no basar únicamente el análisis en un sólo valor de equilibrio.

\section{Gráfica 2}

América Latina 1999-2011 grupo I: Saldo de la belanza comercial como porcentaje del PIB

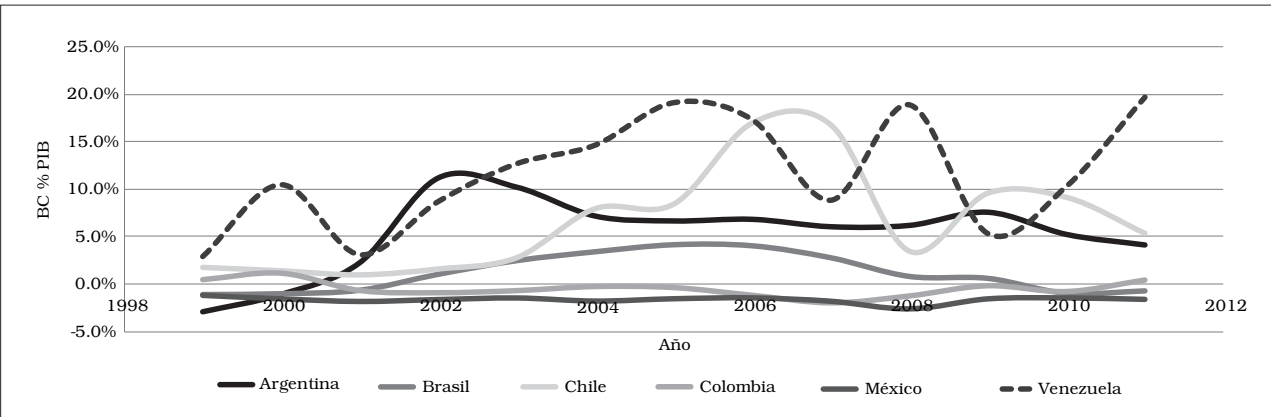

Se puede encontrar aún más evidencia de una posible sobrevaluación del tipo de cambio, si este se ajusta al la Paridad del Poder de Compra del PIB -que calcula la OCDE-, por medio de la utilización de los deflactores del PIB y también incorporando los costos unitarios de la mano de obra de la industria manufacturera, como bien lo sugirió el Banco de México en 1994. ${ }^{11}$

La gráfica 2 muestra los diferentes tipos de cambio teóricos ajustados, incorporando precios (indices de precios al consumidor; deflactores del PIB y PPC del PIB calculados por la OCDE) y competitividad (costos unitarios de la mano de obra de la industria manufacturera), el conjunto de ellos, muestra una tendencia clara hacia la sobrevaluación del tipo de cambio, llama la atención que en dos ocasiones que el tipo de cambio teórico ajustado a los costos unitarios

\footnotetext{
${ }^{11}$ Véase Informe Anual 1994, Banco de México. Donde se señala que el "tipo de cambio real según costo unitario de la mano de obra es un indicador de la evolución de la competitividad internacional de la economía muy superior al que proporciona el tipo de cambio real según índices de precios. Esto, en vista de que el comercio internacional tiende a igualar los precios de los bienes "comerciables" entre los distintos países, cualquiera que sea el tipo de cambio" (p. 85).
} 
laborales cae, en 1998 en $2.4 \%$ a 8.92 pesos por dólar representado el valor de mercado en 9.14 pesos y en 2009 en una cuantía de $11 \%$ a 12.04 pesos por dólar siendo el valor de mercado 13.51 pesos. Ambas caídas se explican por la caída del índice de los costo unitario laboral en México y Estados Unidos, en la misma medida para 1998, pero para 2009 se da una fuerte caída del índice únicamente del lado de México, indicando una fuerte caída en la competitividad ante un contexto de crisis económica internacional.

En las cuatro series existe un comportamiento similar de una creciente sobrevaluación del tipo de cambio (véase gráfica 3) al utilizarse los diferenciales de precios y los deflactores del PIB, en cuanto a la PPC del PIB, se observan pequeños márgenes de sobrevaluación pero con una tendencia estable a pesar de las constantes depreciaciones que ha sufrido la moneda en términos nominales.

El creciente margen de sobrevaluación de la moneda que se muestra podría dar indicios de la magnitud de la depreciación de la moneda si se acompaña junto con un análisis de la balanza de pagos, principalmente en la viabilidad de poder mantener el superávit de cuenta de capital. El tipo de cambio teórico ajustado a los deflactores del PIB indican los mayores márgenes de sobrevaluación, registrando en 2008 una apreciación del tipo de cambio de 48 y 46\% en 2011 . Le sigue el tipo de cambio teórico considerando los índices de precios -hipótesis del PPC- mostrando niveles de apreciación del tipo de cambio en 2001 y 2002 de 37\% y en 2007 de 28 por ciento.

\section{Gráfica 3}

América Latina 2010:

\section{Estructura de las exportaciones totales de la región (18 países)}

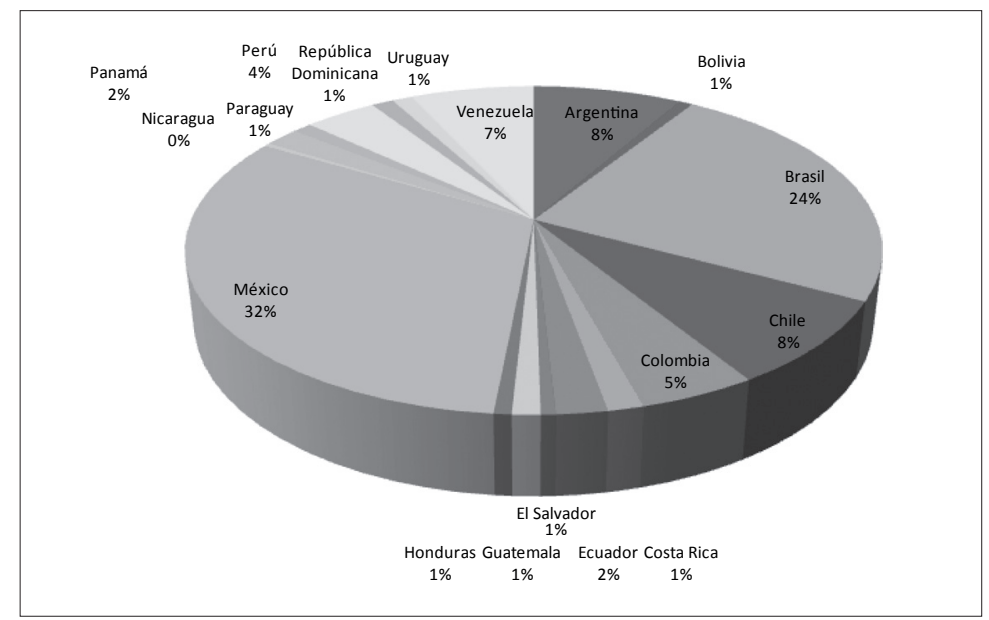


De todo lo anterior ¿qué se desprende? A partir de las diferentes metodologías empleadas para el cálculo del tipo de cambio teórico, se muestra evidencia empírica para afirmar que el actual régimen de tipo de cambio ha logrado apreciar la moneda nacional considerablemente. Para aspectos metodológicos, cuando se hable de la apreciación del tipo de cambio, se estará haciendo en términos del tipo de cambio teórico calculado a partir de la hipótesis del PPC, lo que sería equivalente a hablar de la sobrevaluación del peso mexicano.

\section{Flujos de capital y movimientos del tipo de cambio}

Durante las últimas décadas, México ha presentado constantes apreciaciones del tipo de cambio nominal como resultado de la entrada masiva de capitales del exterior, principalmente especulativos. Por lo que las fluctuaciones del tipo de cambio han pasado a depender fuertemente de los movimientos de capitales en nuestra economía mas que del movimiento de las mercancías.

El constante crecimiento del superávit de cuenta de capital ha venido acompañado de los fuertes diferenciales de la tasas de interés y ha permitido que tales inversiones incrementen y permanezcan en el país, a su vez que el tipo de cambio nominal ha tendido a apreciarse.

\section{Cuadro 4}

\section{Flujos de Divisas 2000-2012 Millones de Dólares}

\begin{tabular}{|r|r|r|r|r|r|}
\hline Año & $\begin{array}{c}\text { Inversión } \\
\text { directa }\end{array}$ & $\begin{array}{c}\text { Inversión } \\
\text { de cartera }\end{array}$ & $\begin{array}{c}\text { Deuda } \\
\text { Externa Neta }\end{array}$ & $\begin{array}{c}\text { Reservas } \\
\text { Internacionales }\end{array}$ & Remesas \\
\hline 2000 & 18282 & 371 & 70260 & 33555 & 6573 \\
\hline 2001 & 29962 & 1022 & 69808 & 40091 & 8895 \\
\hline 2002 & 23901 & -75 & 71528 & 46099 & 9814 \\
\hline 2003 & 18672 & 636 & 73626 & 56086 & 15139 \\
\hline 2004 & 24855 & 2528 & 75713 & 61496 & 18332 \\
\hline 2005 & 24449 & 6046 & 65723 & 68669 & 21688 \\
\hline 2006 & 20292 & 5319 & 47247 & 67680 & 25567 \\
\hline 2007 & 31380 & 7329 & 34533 & 77894 & 26059 \\
\hline 2008 & 27853 & 2430 & 24319 & 85274 & 25145 \\
\hline 2009 & 16561 & 7634 & 91722 & 90838 & 21306 \\
\hline 2010 & 21372 & 23500 & 104679 & 113597 & 21304 \\
\hline 2011 & 21504 & 25086 & 113632 & 142476 & 22803 \\
\hline 2012 & 12659 & 56678 & 121659 & 163592 & 22446 \\
\hline
\end{tabular}

Fuente: Banco de México y cálculos propios. 
En el cuadro 4 se puede observar el flujo de divisas hacia nuestro país del periodo que va del 2000 al 2005, en el cual resalta el incremento drástico de la inversión de cartera ya que para 2012 representó ciento cincuenta y dos veces su valor en el año 2000. También resalta el incremento de más en las reservas internacionales, ya que para 2012 cuadruplicó su valor.

Existe una creciente tendencia hacia la apreciación del tipo de cambio. El problema, radica en el plazo y propósito qué tengan dichos capitales en la economía mexicana, ya que colocan en una fuerte vulnerabilidad a la economía por ser capitales especulativos.

El creciente flujo de capitales ha ido acompañado a su vez de un incremento en el monto de las reservas internacionales en poder del banco central para hacer frente a cualquier ataque especulativo o salida masiva de capitales. Es importante recordar que ello no es requisito al trabajar bajo un régimen de tipo de cambio flotante, ya que no se compromete la convertibilidad de la moneda a una paridad fija.

\section{Gráfica 4}

América Latina 2010: estructura de las importaciones (18 países)

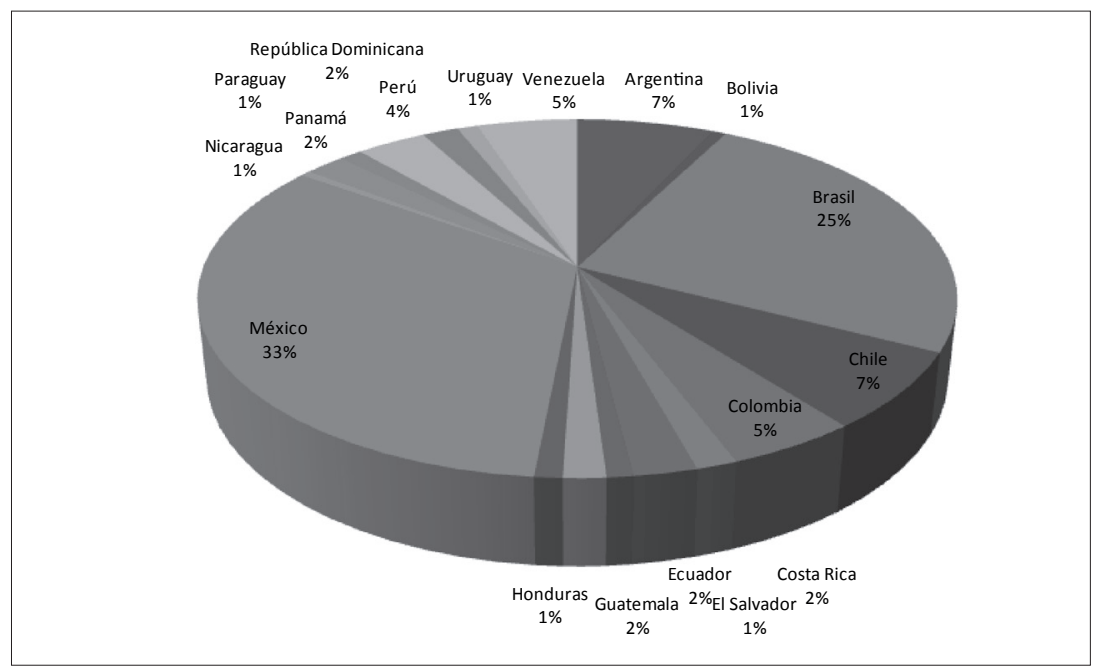

Huerta (2001) encuentra una fuerte relación entra la estabilidad cambiaria y el comportamiento de la cuenta de capital, al señalar que existe una fuerte necesidad del gobierno de garantizar el flujo de capital para estabilizar las 
fluctuaciones del tipo de cambio (p. 56). Por ello existe un co-movimiento crecimiento del superávit en la cuenta de capital y la apreciación del tipo de cambio como se observa para el periodo de 2000-2012.

De lo anterior se desprende que, si bien, la economía mexicana ha visto incrementado el flujo de divisas, esto ha sido por medio de mantener atractivas tasas de retorno para los capitales, lo que se ha visto reflejado en una constante apreciación del tipo de cambio nominal y que ha requerido de ir de la mano de un incremento exponencial de las reservas internacionales, que han pasado a jugar un papel preponderante para hacer frente a cualquier salida de capitales por medio de la intervención en el mercado cambiario.

\section{Bibliografía}

Banco de México, “Sistema Financiero”, www.banxico.org.mx Recuperado el 21 de febrero de 2013, de http://www.banxico.org.mx/divulgacion/sistema-financiero/sistema-financiero.html\#niveladecuadodereservasinternacionales

----- "Esquema de Objetivos de Inflación”, www.banxico.org.mx Recuperado el 18 de febrero de 2013, de http://www.banxico.org.mx/politica-monetaria-e-inflacion/material-de-referencia/intermedio/politica-monetaria/\{5C9B2F38-D20E8988-479A-922AFEEBB783\}.pdf

----- Informe Anual 1994, www.banxico.org.mx Recuperado el 8 de mayo de 2013, de http://www.banxico.org.mx/publicaciones-y-discursos/publicaciones/informesperiodicos/anual/\{F1A00075-21D4-5DCF-D124-09CB6EF16235\}.pdf

Baqueiro, et al. (2003), “¿Temor a la Flotación o a la Inflación? La Importancia del ‘Traspaso' del Tipo de Cambio a los Precios”, Documento de Investigación núm. 2003-02, Dirección General de Investigación Económica Banco de México.

Calvo, G.A. et al. (2002), "Fear of Floating", vol. cxviI, The Quarterly Journal of Economics.

Esquivel (2010), De la inestabilidad macroeconómica al estancamiento estabilizador: el papel del diseño y la conducción de la política económica, en Lustig, N. Crecimiento Económico y Equidad, Vol. Ix (pp. 35-75), México: El Colegio de México.

Frankel, J.A. (2003), “Experience of a Lessons from Exchange Rate Regime in Emerging Economies", NBER Working Paper No. 10032, National Bureau of Economic Research, Inc.

Guerrero, C. et al. (2007), Reflexiones sobre la Política Cambiaria en México. En Calva, J.L., Macroeconomía del Crecimiento Sostenido. Agenda para el Desarrollo, vol 4, (pp. 155-168) México: UnAM-Miguel Ángel Porrúa. 
Huerta, A. (2011), Cap. 1 “Apreciación Cambiaria como Obstáculo al Crecimiento”, en Obstáculos al crecimiento: peso fuerte y disciplina fiscal (pp. 31-93), México: UNAM.

---- (2001), Cap. 1. "La globalización y la política cambiaria”, en Apreciación cambiaria, baja inflación, recesión económica (pp. 1-41), México: Diana.

International Monetary Fund (2012), "Annual Report of Exchange Arrangements and Exchange Restrictions”, [versión electrónica] (pp. 4-31).

Instituto Mexicano para la Competitividad A. C. (2011), "Más allá de los BRics", www. competitividadinternacional.org Recuperado el 20 de febrero de 2013, de http:// www.competitividadinternacional.org/downloads/f.4.MasalladelosBRICS.pdf

MacDonald, R. (2007), Cap 1. Introduction: Some Basic Concepts and Stylised Facts and the Case for (and Against) Floating Exchange Rates. En "Exchange Rate Economics: Theories and Evidence” (pp. 1-38), Gran Bretaña: Routledge.

Olivera, J. (2012) "Inflación Estructural y Política Financiera”, Anales de la Academia Nacional de Ciencias Económicas Serie 3a, vol. 3, Mayo-Agosto de 2012 (pp. 146-159).

Perrotini, I. et al. (2007), "Inflación, Tipo de Cambio y Regla de Taylor en México 1983-2006”, Equilibrio Económico, Año viII, vol. 3, núm.1, Primer Semestre de 2007 (pp. 27-54).

Williamson, J. (1990), Cap 2. What Washington Means by Policy Reform. en Latin American Adjustment: How Much Has Happened? (pp. 1-38), Estados Unidos: Institute for International Economics.

---- (2000) "What Should the World Bank Think about the Washington Consensus?" The World Bank Research Observer, vol 15, no. 2, The International Bank for Reconstruction and Development.

Wray, R. (2012), Cap 5. Modern Money Theory and Alternative Exchange Regimes, en Modern Money Theory: A Primer on Macroeconomics for Sovereign Monetary Systems (pp. 148-186), Gran Bretaña, Palgrave Macmillan. 